\title{
Biking to Academic Success: A Study on a Bike Desk Implementation at an Academic Library
}

Public Services Quarterly

Jared Hoppenfeld $^{a *}$, Stephanie J. Graves ${ }^{\mathrm{b}}$, Robin R. Sewell ${ }^{\mathrm{c}}$, and T. Derek

Halling $^{\mathrm{d}}$

${ }^{a}$ University Libraries, Texas A\&M University, College Station, USA; ${ }^{b}$ University Libraries, Texas A\&M University, College Station, USA; ' University Libraries, Texas A\&M University, College Station, USA; ${ }^{d}$ University Libraries, Texas A\&M University, College Station, USA

*Address correspondence to Jared Hoppenfeld, Associate Professor, Director of West Campus Library and Policy Sciences and Economics Library, Texas A\&M University, TAMU 5001, College Station, TX 77843-5001, USA. E-mail: jhoppenf@tamu.edu 


\title{
Biking to Academic Success: A Study on a Bike Desk Implementation at an Academic Library
}

\author{
Sedentary behavior has increased over the last several decades, and this has led to major \\ life-threatening health issues. Texas A\&M University Libraries has introduced an \\ innovative idea in three of their buildings. This case study highlights the implementation \\ of Bike Desks at an academic library while offering strategies for other libraries wishing to \\ replicate this project, and analyzes data from a user survey. The survey explored student \\ experiences, including perceived satisfaction and any perceived gains in study habits while \\ using the Bike Desk.
}

Keywords: academic libraries; bike desk; student success; exercise; innovation

\section{Introduction}

Libraries are developing new ways to engage and reach users. One novel way of approaching user engagement is exploring linkages between academic achievement and bodily health. During the summer of 2017, Texas A\&M University Libraries purchased six Bike Desks, which were placed in three of the College Station campus library buildings. Bike Desks are stationary bicycles with an attached desktop, which allows users to pedal while engaging in academic activities. This case study highlights the project implementation, offers strategies for a successful Bike Desk project for other libraries, and analyzes data from a user survey. Survey questions asked about the frequency of use of the Bike Desk, perceived satisfaction with the experience, and any perceived gains in study habits through use of the Bike Desk. The Bike 
Desk project aimed to answer the following research questions:

1. Are there patterns of Bike Desk use based on demographics or self-reported current physical activity?

2. Are Bike Desks used as a solitary activity or with another person?

3. Does the availability of Bike Desks impact usage of the library facilities?

4. Are Bike Desk users more likely to study or engage in other leisure activities while using the Bike Desk?

5. Does use of the Bike Desk result in self-reported increase in academic achievement?

6. Are library users who use the Bike Desks satisfied with the experience?

The results of the project were used to determine future library investment in additional Bike Desks, to evaluate the level of interest in potential health-improving activities in the library, and to explore any academic benefits to offering these services in the library facility.

\section{Literature Review}

\section{Sedentary Culture}


Americans are increasingly in a physical state of inactivity both at home and in the workplace. According to Young et al., average weekly sedentary time in the U.S. increased from 26 hours in 1965 to 38 hours in 2009, and within that same period of time, the percentage of sedentary occupations also increased, from $15 \%$ in 1960 to $20 \%$ in 2008 (2016). This is cause for concern as there is "evidence accumulating that indicates greater time spent in sedentary behavior is associated with all-cause and cardiovascular morbidity and mortality in adults" (Young et al., p. 262) as well as "contributing to the rising prevalence of the obesity epidemic" (Villablanca et al., 2015, p. 509).

Villabanca et al. found that a focus on moderate to vigorous-intensity physical activity during discretionary time resulted in limited success in the reduction of cardiovascular events and referred to an alternate strategy of reducing total sedentary time with light activity (2015). Their research focused on non-exercise activity thermogenesis, or NEAT, which represents "common daily activities, such as fidgeting, walking, and standing" (Villablanca et al., p. 509). Young et al. stated that many in the workplace have used "activity-permissive workstations" which have enabled "office workers to stand, walk, or pedal while working at their usual computer and other desk-based job tasks" (2016, p. 271). According to Villablanca et al., these types of NEAT activities increase calories expended as well as reduce the occurrence of metabolic syndrome, cardiovascular events, and all-cause mortality. College students are not immune to these same sedentary influences. In fact, numerous studies have been completed on the physical activity of college students (Dinger, 1999; Pauline, 2013; Soyeur, Unalan, \& Elmali, 2010; Towne et al., 2017; Young, Sturts, \& Ross, 2015), which have found that their respondents are not meeting the recommended levels of physical activity. 
Soyeur, Unalan, and Elmali (2010) attributed this to students possessing greater freedom when they begin college and having more control over their lifestyles than previously. Pilcher, Morris, Bryant, Merritt, and Feigl (2017) stated that many college students lead "largely sedentary lives due to their time in class and time studying” (p. 2) while Towne et al. cite another cause, having proclaimed that the "growing use of technology has been suggested as a possible contributor to lower physical activity levels among the global community" (as cited in $\mathrm{Ng} \&$ Popkin, 2012). Potential use of laptops and other mobile devices while using a Bike Desk could very well address this issue as alluded to in the research of Dinger (1999), which stated that "proximity and convenience are important determinants of physical activity participation" and has suggested exploring "possible ways to make physical activity participation more convenient for all students" (p. 147). The placement of Bike Desks in university libraries provides students with another convenient location in which they may exercise.

\section{Effects of Physical Activity on Academic Performance}

Benefits of exercise while performing work tasks or schoolwork are evident in the literature. Bryant et al. (2015) and Pilcher et al. (2017) published about research performed at Clemson University in which they studied the effects of light activity (the use of Bike Desks) on academic performance and sleep quality. While Soyeur, Unalan, and Elmali (2010) reported that fatigue is related to impaired academic performance (as cited in Nagane, 2004), Bryant et al. found that

those who rode the bikes while performing schoolwork maintained better sleep quality, which correlated positively with academic performance. They also reported that "acute exercise has 
been shown to increase the speed of information processing, improve executive function, enhanced cognitive flexibility, as well as working memory” (Bryant et al., 2015, p. 1).

Similar results have been reported in the workplace. In comparing an activity workstation, which included a bike, with a traditional desk, Pilcher and Baker (2016) found that cognitive task performance did not change due to light activity on the stationary bike, and this activity had no detrimental effect on performance. They also observed improvements in motivation and morale when using the bikes, as well as improved problem solving and decision making.

\section{Bike Desks in Libraries}

With the previously mentioned positive correlation between light physical activity and performance in the workplace and classroom, numerous libraries have added Bike Desks to their facilities for varied health-related reasons. The University Dean of Library Services at Troy University installed the bikes to combat a previously mentioned issue that technology has caused people to become "sedentary creatures," which has led to obesity (Shaffer, 2016). Light activity on Bike Desks can help with this as bicycling can burn 100-200 calories per hour (Villablanca, 2015, p. 514). Pilcher et al. (2017) reported that in addition to addressing obesity and heart disease, research has shown that light or moderate activity may decrease anxiety (as cited in Fox, 1999) and lead to an improved quality of life (as cited in Oka et al., 2000). The Kresge Library purchased two bikes "as an alternative, health-oriented work station, in keeping with the wellness goals of Oakland University" (Pedal, 2016). 
With these benefits in mind, several other academic libraries have included Bike Desks in their public spaces. In addition to the 22 purchased at Clemson University (Logue, 2015), hundreds of bikes have been implemented at dozens of academic libraries, including Winthrop University (Friends, 2016), Troy University (Shaffer, 2016), Duke University (Riegel, 2017), Oakland University (Pedal, 2016), Harvard University, Florida State University, the University of California in Los Angeles, and Mississippi State University (Logue, 2015).

Along with the health benefit associated with having Bikes Desks in libraries, the implementation of this equipment can also serve as a clever outreach opportunity, a way of drawing students into the library. The University Dean of Library Services at Troy University in Alabama, who installed six bikes, claimed, "In an era when people tend to think that everything can be found via Google, it is important to find creative ways to bring people back to the library where they can receive help getting the information they truly need" (Shaffer, 2016). Logue reported a similar notion by the President of Wake Technical Community College in North Carolina, whose library purchased two bikes, as he wanted "to have a little something different that gets [students] excited about coming to the library" (as cited in Stancill, 2015).

Academic libraries are not alone in this effort, as public libraries have also promoted healthy work habits with Bike Desks. New Hanover County Public Library received an Innovation Grant from North Carolina State Library to purchase their exercise bicycles (Nolan, 2015). In an interesting twist, when pedaled, some of their bikes create energy to power tablets while others are connected to bubble machines, giving children motivation to exercise. A 
drawback to these bikes is the noise produced while in use, something considered at Texas A\&M and was addressed in the survey results.

\section{Project Background and Implementation}

This case study took place at Texas A\&M University Libraries, which serves the faculty, staff, and students of the Texas A\&M College Station campus. The library system is comprised of five locations spread across the large campus of more than 5,200 acres. The total enrollment exceeded 63,000 students in 2017 and is growing annually. Undergraduates account for more than $80 \%$ of the student population, who are enrolled in over 128 degree programs, while there are 268 graduate degree programs, ranging from professional to doctoral degrees. There is insufficient on-campus housing for such a large university, so the majority of students live in apartment complexes adjacent to campus, commute, and remain on campus until their last activity or class has finished. Due to the convenient proximity for those living on campus and a diverse academic study environment for all students, the University Libraries are a popular hub of student activity throughout the day and into the late night hours.

Texas A\&M University Libraries prides itself with trying innovative ideas to support the university's faculty, staff, and students. Upon hearing about the installation of FitDesk's Bike Desks at Troy University from a colleague, one of the authors did further research, reading Shaffer's article in American Libraries (2016) and a poster session by Bryant et al. (2015). The research included the study performed at Clemson University, which found that light activity had a positive effect on sleep quality and academic performance. In an effort to offer an equally innovative and beneficial experience for users, Texas A\&M University Libraries purchased six 
Bike Desks for three of their libraries: Sterling C. Evans Library \& Annex (the main library), West Campus (Business) Library (WCL), and Medical Sciences Library (MSL). A team of interested librarians from the three locations came together to form the Bike Desk Team. It was decided to use the same model bike that the authors had read about in the literature so they purchased directly from the vendor FitDesk. At \$299 each, the investment and level of financial risk was minimal.

Prior to the procurement of the bikes, preliminary efforts were put in place to ensure a successful implementation. An important part of this planning effort was ensuring the participation of the Libraries' Marketing and Communication team; the Bike Desk Team met with Marketing four months prior to installation. Marketing efforts in support of the Bike Desk implementation included the following:

- banners, news articles, and FAQ pages on the Libraries' website,

- posters and digital signage throughout the Libraries,

- education of front desk staff,

- an email sent to all library staff,

- a presentation made at the monthly all-library staff meeting, and

- $\quad$ pictures sent over social media.

In addition to Marketing, the team collaborated with Library Human Resources and the university's Risk Management office to explore any legal ramifications of installing the Bike 
Desks in the libraries. The team was advised to have a maintenance log attached to the Bike Desks and to make information available for whom to contact should there be an issue with a bike.

The Bike Desks did not come assembled so library staff had to put them together when they arrived. Besides a missing part for one of the six bikes, the process went smoothly. For purposes of this study, all six Bike Desks were put in place on the same day. Two were placed next to each other on the 4th floor of Evans Library, two next to each other on the 2nd floor of the West Campus Library, and two were placed in separate parts of the Medical Sciences Library. The decision to locate the six Bike Desks at three different library locations was intentional in order to serve a diverse group and reach the maximum number of possible students. Each of the libraries serves distinct populations of students, as each building is intentionally located near the departmental buildings that serve specific majors and programs. There are two additional library buildings on campus that did not receive a Bike Desk. The Bike Desk Team did not see the utility of placing a Bike Desk in the special collections facility and the small, two-room library outpost near the edge of campus.

To address health and safety concerns, sanitary wipes and dispensers were purchased and placed adjacent to each Bike Desk so users could wipe down seats, handles, and desks, if desired. Monthly maintenance of the Bike Desks included tightening the pedals (the only suggested maintenance by the vendor), checking the batteries in the odometers, and filling the wipes dispensers if needed. These are all included on a maintenance log attached to each bike and initialed once completed. 
Once the Bike Desks were deployed, the team developed several methods to track usage and gather feedback from users.

\section{Methodology}

The team determined that the collection of Bike Desk usage statistics would be challenging and decided on a two-pronged approach that employed a Qualtrics-based user survey and staff observation. Combined, the expectation was that the two methods would provide a more complete picture of use than either would alone. The Qualtrics survey provided additional data on who used the Bike Desks and how they were used. The researchers recognized the limitations of both methods: the Qualtrics survey relied on self reporting which is not always accurate (Adams et al., 2005, Phillips \& Clancy, 1972) and manual counts only captured Bike Desk use at a specific moment in time.

Because the survey would only record information for a limited population (i.e., those who chose to participate), manual Bike Desk usage counts were collected hourly by staff and students at each library location, and the number of users was recorded for each Bike Desk on a spreadsheet. This process was an additional task to normal checks already in place at the Evans and West Campus libraries. Since similar practices were not already in place at the Medical Sciences Library, a retired gate count reminder was repurposed to alert staff and students to check for Bike Desk use. 
The researchers obtained Institutional Review Board approval to administer the online survey to human subjects. A Qualtrics survey was used to gather demographic data, which included current level of physical activity, activities performed while using the Bike Desks (academic, non-academic, or both), and level of satisfaction. Display logic was used to guide users through the survey based on answers already provided. For example, MSL had Bike Desks in two separate locations; if the patron selected MSL as the library location, they were not asked if they rode alone or with a friend. Likewise, if an individual selected the answer "Studied/Academic Activities," they were not asked follow-up questions related to non-academic activities. To improve the survey response rate, the researchers promoted a drawing to be held at the end of the research period for two Fitbits, which were purchased with funds from the Libraries Research Committee. Individuals who completed the Bike Desk survey had the option of continuing to a linked Fitbit drawing Qualtrics survey that would collect their name and email for entry into the drawing. There was no association between the personal data (name and email) and answers given on the Bike Desk survey. The survey ran from August 1, 2017 to October 31, 2017 during the busiest period of the fall academic term.

\section{Results}

The Qualtrics survey recorded 184 responses, of which 152 respondents completed the survey. The data from the survey was analyzed to answer the research questions defined at the outset of the project. 


\section{Q1: Are there patterns of Bike Desk use based on demographics or self-reported current physical activity?}

Demographic data from the survey indicated some trends in the use of the Bike Desks by certain populations. Survey respondents were predominantly undergraduate students $(n=108 ; 71 \%)$. The next largest group were graduate students $(n=32,21 \%)$, followed by professional students $(n=5$, $3 \%)$, faculty and staff $(n=5,3 \%)$, and others $(n=2,1 \%)$. Survey respondents were split evenly across gender with 77 male respondents and 75 female respondents.

The location of the Bike Desk being used was also recorded in the survey data. This was particularly interesting information to uncover as it could be used to determine whether Bike Desks in certain locations were more likely to get used than others. Results indicated that the bikes used most often were located in the Evans Library facility, the largest library on campus $(\mathrm{n}=90,59 \%)$. The next most used location were the Bike Desks located at the Medical Sciences Library $(n=35,27 \%)$, followed by the West Campus Library with approximately $18 \%$ of the usage $(n=27)$.

Another data point gathered was at what time respondents used the Bike Desk and for what duration. Figure 1 shows the time of day as reported by users. Bike Desks were most often used during the middle of the day, between 1:00 and 7:00 p.m. With 152 reported rides in the survey data, there was a large variance in ride length. Survey respondents indicated rides as brief as 1 minute and as long as 180 minutes. The average ride was approximately 33 minutes with a standard deviation of 31 minutes across all rides. 
Figure 1: Bike Desk Riders by Time of Day.

\section{Bike Desk Riders by Time of Day}

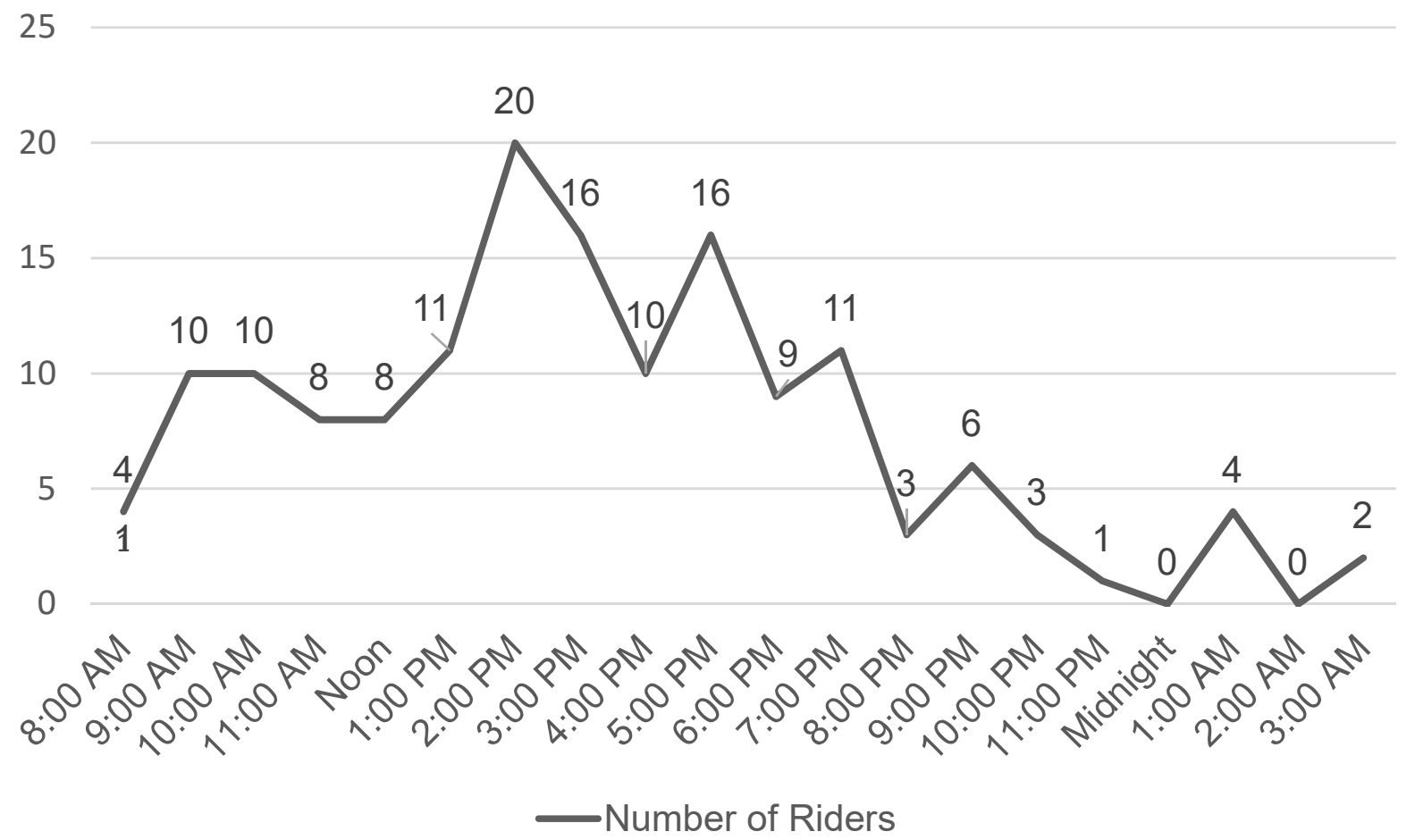

The survey also asked users to self report their level of weekly physical activity. Users who reported exercising between 1-6 times a week made up the majority of the Bike Desk users. There were five cases reported in which the survey respondents said that they never exercised but did use the Bike Desks, one of whom rode for 180 minutes. The length of time spent riding was compared with self-reported activity level and is represented in Table 1 . The average riding time does appear to increase based on activity level. 
Table 1: Current Level of Physical Activity Compared to Length of Ride

\begin{tabular}{|l|l|l|l|l|l|l|}
\hline & \multicolumn{6}{|c|}{ Time on Bike in Minutes } \\
\hline Activity Level & $\begin{array}{l}\text { No. of } \\
\text { Respondents }\end{array}$ & Minimum & Maximum & Mean & $\begin{array}{l}\text { Std. } \\
\text { Deviation }\end{array}$ & Variance \\
\hline None & 5 & 10 & 180 & 60.2 & 60.93 & 3712.16 \\
\hline 1-3 times/month & 16 & 5 & 60 & 23.06 & 16.41 & 269.43 \\
\hline 1-2 times/week & 45 & 2 & 70 & 28.93 & 18.09 & 327.4 \\
\hline 3-4 times/week & 56 & 1 & 165 & 33.32 & 32.36 & 1047.47 \\
\hline 5-6 times/week & 21 & 1 & 80 & 32.81 & 21.63 & 467.87 \\
\hline $7+$ times/week & 9 & 10 & 180 & 62.22 & 51.59 & 2661.73 \\
\hline
\end{tabular}

Because the survey would only record information for a limited population (i.e., those who chose to participate), the researchers collected Bike Desk usage data by having staff record hourly counts on a tick sheet that was transferred to a spreadsheet. This secondary approach to data collection was intended to help the researchers get a more accurate picture of usage. Unfortunately, analysis indicated that this data gave very little useful information. Since the majority of users rode for less than one hour's duration, staff often missed seeing someone on the Bike Desks. Because staff did not record the exact time, only the hour in which they witnessed someone on the bikes, it was impossible to correlate survey data with the manual counts of usage.

Q2: Are Bike Desks used as a solitary activity or with another person? 
The researchers wanted to investigate if students would be more likely to ride the Bike Desks alone or with others. In order to uncover the possible social nature of riding the bikes, the survey instrument asked respondents if they rode alone or with a friend. The majority of respondents rode alone $(n=83,71 \%)$ while a far smaller amount chose to ride with a partner $(n=34$, 29\%). This data excludes the 45 users that rode the Bike Desks at the MSL location because the only option was to ride alone. When analyzed by gender, men were more likely to ride alone $(n=50,60 \%)$ than were female respondents $(n=33,40 \%)$, as seen by Figure 2 .

Figure 2: Riding Alone or with a Friend by Gender.

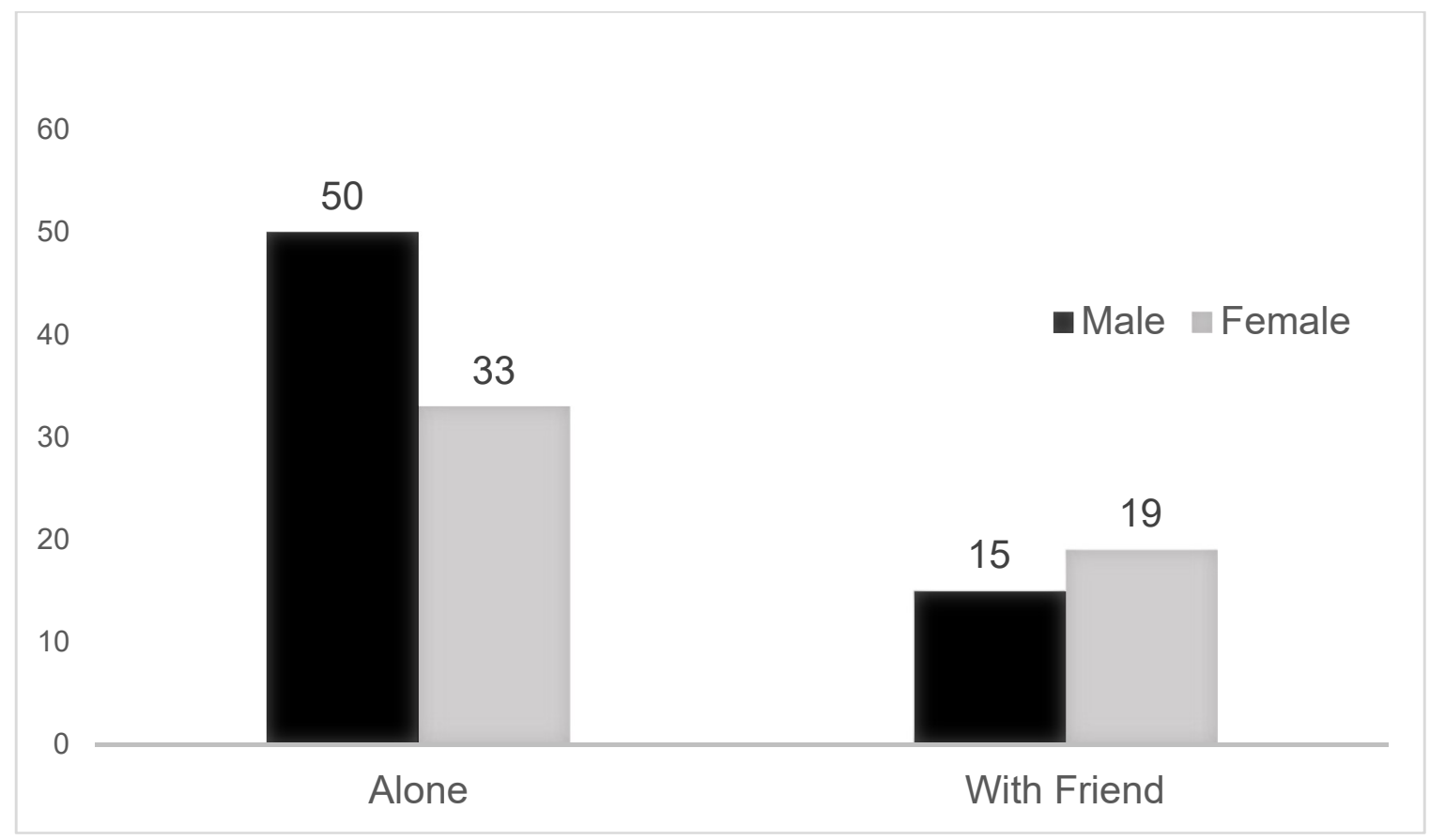


Figure 3: "I am more likely to study at the library if I can use the Bike Desk."

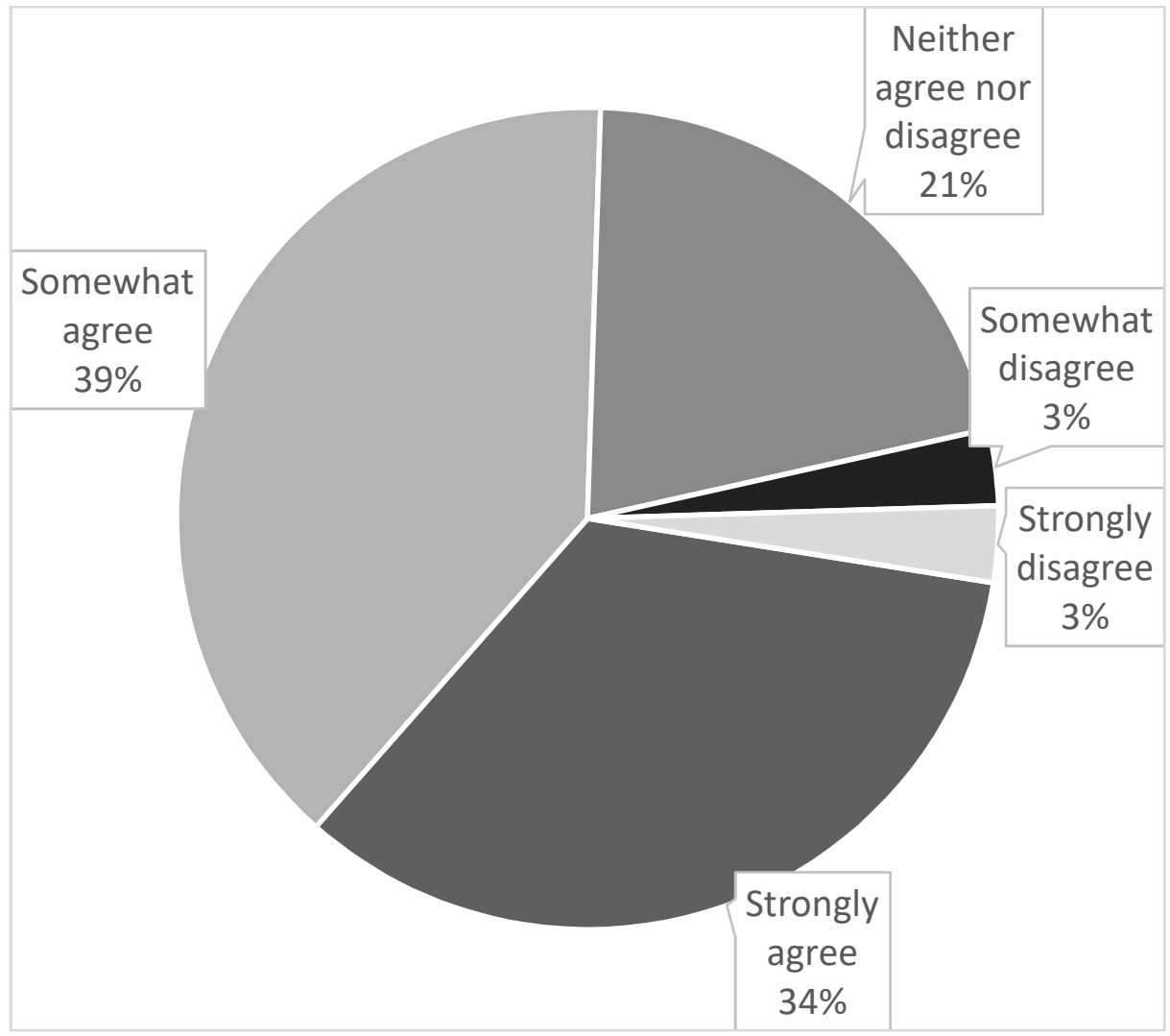

Q3: Does the availability of Bike Desks impact usage of the library facilities?

The researchers wished to understand any impact that the availability of the Bike Desks may have on library usage. Therefore, survey respondents were asked if they were more likely to study at the library if they could use a Bike Desk. Feedback was overwhelmingly positive, with $73 \%$ of respondents indicating that they strongly agreed or somewhat agreed. Another $21 \%$ indicated that the Bike Desks did not have an impact on their likelihood of studying at the library while only $6 \%$ of respondents either somewhat disagreed or strongly disagreed. 


\section{Q4. Are Bike Desk users more likely to study or engage in other leisure activities while using the Bike Desk?}

Bike Desk users could choose to study or engage in leisure activities, such as watching movies or listening to music, while riding. In order to gauge the frequency of academic-related activity during Bike Desk use, the survey asked a series of questions about in what tasks users engaged while riding and what tools they used. The majority of survey respondents reported engaging in academic activities while riding $(n=99,65 \%)$. Of those that did not study while using the Bike Desk, respondents were evenly split between those that just rode the bike $(n=29,19 \%)$ and those that engaged in non-academic activities $(n=24,16 \%)$.

Survey respondents were then asked to indicate in what type of non-academic activities they engaged while riding. Because respondents could select more than one non-academic activity, the total number of responses $(n=45)$ exceeded the number of respondents who indicated that they used the Bike Desk for non-academic activities $(n=24)$. Table 2 lists the types of nonacademic activities indicated in the survey. Surfing the web was the most popular choice, followed by social media, listening to music, people watching, and reading for entertainment. 
Table 2: Non-Academic Activities Performed While Using Bike Desk.

\begin{tabular}{|l|c|c|}
\hline Activity & Percentage & Count \\
\hline Surfed the Web & $24 \%$ & 11 \\
\hline Social Media & $20 \%$ & 9 \\
\hline Listened to music & $16 \%$ & 7 \\
\hline People watched & $16 \%$ & 5 \\
\hline Read for entertainment & $11 \%$ & 3 \\
\hline Watched YouTube & $7 \%$ & 2 \\
\hline Other & $4 \%$ & 45 \\
\hline Watched Movies/DVDs & $2 \%$ & 1 \\
\hline Total & $100 \%$ & \\
\hline
\end{tabular}

Respondents were also asked to indicate what types of tools and technology they used while riding the bike. Respondents were able to select multiple tools, and 239 answers were recorded. The most popular tools used were laptops and cell phones at $29 \%$ and $27 \%$ respectively. Books were used $14 \%$ of the time, and audio devices were used $11 \%$ of the time. Notes, writing tools, and tablets accounted for the remaining $15 \%$ of tools used while riding.

\section{Q5. Does use of the Bike Desk result in self-reported increase in academic achievement?}

Researchers gathered self-reported data on users' perceptions of Bike Desk use and academic studies. Survey respondents were asked if they felt using the Bike Desk "helped you in your studies" $(\mathrm{n}=99)$. More than half affirmed that they perceived the Bike Desk to be helpful to their 
academic studying, with 18 answering "definitely yes" and another 40 respondents answering “probably yes" (n=58). Approximately a third of respondents were unsure $(n=36)$, answering that the Bike Desks "might or might not" have helped them in their studies. Only five percent $(n=5)$ reported the Bike Desk as unhelpful to their studies; two respondents answering "probably not" and three answering "definitely not".

Q6: Are library users who use the Bike Desks satisfied with the experience?

Survey respondents were asked to report their satisfaction with the comfort, availability, and location of the Bike Desks, as well as their overall satisfaction with the experience. Respondents were overwhelmingly satisfied with the Bike Desks, as depicted by Figure 4.

Figure 4: User Satisfaction with Bike Desks.

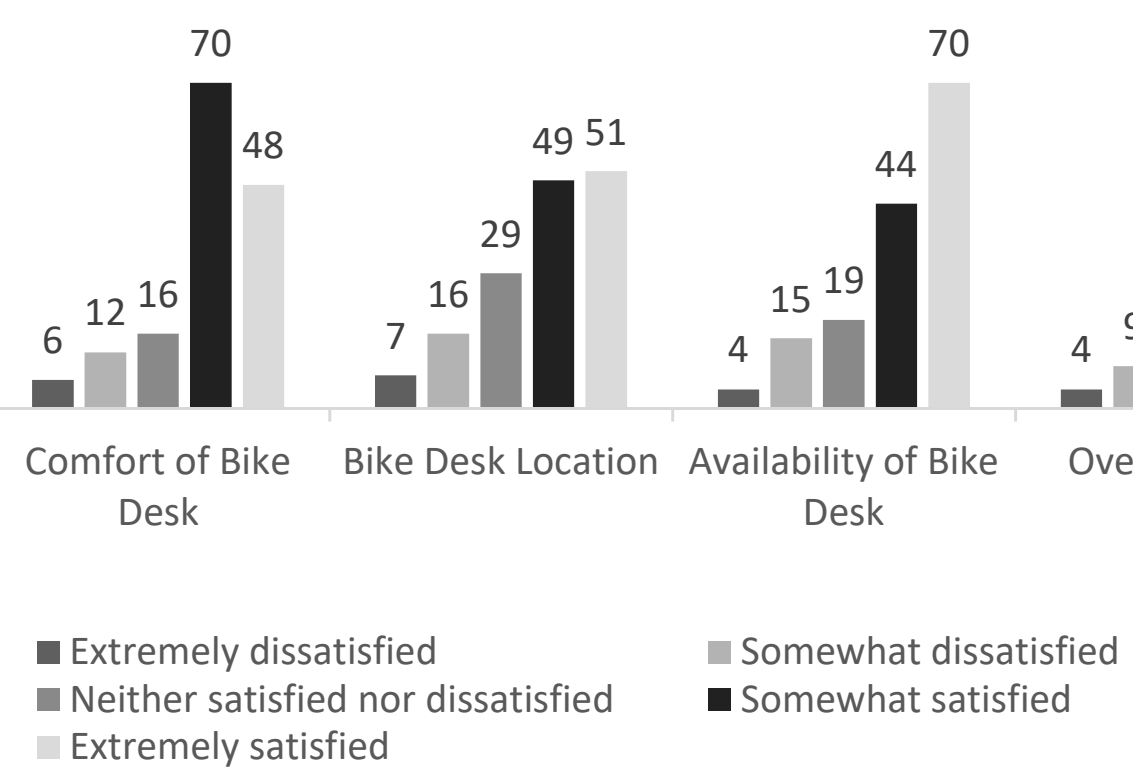


In addition to the collection of quantitative data, the survey also included an area for respondents to leave comments. Out of 152 valid surveys, 82 users left a comment in the open comment field at the end of the survey, a 54\% response rate. Comments were coded using inductive qualitative analysis and thematic reduction. Themes emerged that addressed general feelings about the Bike Desks; issues with function, location, and privacy; and comments about the use of the bikes related to academic study. Comments could have multiple codes, as many comments addressed several themes.

General affirmative statements accounted for the majority of the coded comments. These were coded as "Happy," and included statements such as "The Bike Desk was awesome" and "I love the Bike Desks!!" Another 11 comments were coded as "More." These were comments that simply stated that the Libraries should invest in more Bike Desks and place them in more locations; another indication that users are satisfied with the bikes. Only three negative statements were coded as "UnHappy," with comments such as, "this is a waste of money..."

The next largest category was "Adjust" $(n=31)$, which included comments about the comfort of the Bike Desk seat, problems adjusting the height of the seat, and issues with unstable surfaces. Indeed, a large number of users commented that they were too short to effectively use the bikes and that the seat did not adjust appropriately for their height. The next theme that emerged was "Location." The placement of the Bike Desks was mentioned 22 times. Some users wanted the bikes closer to outlets or in other areas of the library that were more collaborative/receptive to noise. However, the largest percentage of comments in this area were related to privacy. Ten respondents specifically mentioned feeling awkward exercising within 
public view and wishing the Bike Desks were located in a more private area. One respondent's comment was as follows:

The Bike Desk suffers from the fact that they are all located in open spaces where others can watch. Many feel uncomfortable using the bike because there are those around them who are not exercising, so it causes the user to stand out and draw unwanted attention to themselves. For optimal placement, the Bike Desks should be placed in private study rooms so that the user does not feel out of place.

The final themes were related to how use of the Bike Desks correlated to quality of study. Thirteen comments were coded as "Focus," with users specifically mentioning an increase in their ability to focus on studying while using the Bike Desk. An additional 12 comments were coded for "Multi-tasking." In particular, these user comments stated that the ability to multitask (e.g., exercise while studying) was useful. One user stated, "I am amazed that I can study and exercise at the same time." Another stated, "I get to alleviate my stresses [sic] level by exercising while studying." Finally, there was a theme coded as "Change of Pace" $(n=8)$. These comments were unique because instead of using the Bike Desk simultaneously while studying, these students viewed the Bike Desk as a positive break to help increase the time they could stay on task. One example included the following statement: "It is always hard for me to stay still or awake while studying, so I take walks. With the Bike Desk, that is not a problem." 


\section{Discussion}

According to the overwhelmingly positive survey responses, students enjoy not having to choose between studying and staying physically active. In giving the students the opportunity to perform both of these activities simultaneously, Texas A\&M University Libraries has provided a value-added service.

Despite the warm reception, the survey feedback did pick up on areas for iterative improvement that could lead to a better user experience, such as privacy and mechanical issues with the bikes.

The Bike Desk project was also a successful alternative for user engagement. Several survey respondents even indicated that the Bike Desks served as a draw to get students into the library facilities. Students have a variety of choices on when and where to spend their valuable time. Survey results indicate that the Bike Desk project was a success in the eyes of the users, with indications that the Bike Desks had an impact on their willingness to study in the library. This matches with anecdotal evidence gathered from staff (e.g., some students came dressed specifically to use the Bike Desks). Furthermore, quantitative feedback and open comments both show that students found physical activity improved their ability to study. If success of the project is measured in the ability to draw students into the library and improve learning, then the Bike Desk project is a resounding success. 
In addition to gathering feedback from users, the research team was pleasantly surprised by the positive media attention that the Bike Desks generated for the library. The project was covered by local media, which was later picked up by American Libraries Online. The media coverage led to more than two dozen contacts from libraries both nationally and internationally to gain advice on similar projects in K-12 schools as well as academic and public libraries.

\section{Limitations and Next Steps}

There are acknowledged limitations to the survey data. The results of the survey are limited to the local context of this case study and cannot be generalized. Furthermore, survey statistics were generated from self-reported data from only those users that decided to take the survey. Results may not be reflective of the total Bike Desk user population on campus, and there may be reporting bias in responses to questions dealing with physical activity (Adams, et al. 2005). In particular, the researchers were interested in how the Bike Desks could impact academic success. User perceptions were positive in the survey data, but no direct correlations could be drawn from this survey study between physical activity and metrics of academic success such as grades. Further study would need to be done in this area if any academic achievement gains were to be linked to the Bike Desks or other physical activities in libraries.

An additional limitation on the usage statistics was the ineffectiveness of the hourly ticksheet used by library staff. Hourly checks on the use of the Bike Desks were not very productive as they were done inconsistently by staff, and many Bike Desk riders rode for less than an 
hour. Without additional methods for tracking usage such as a sensor in the seat or relocation of the Bike Desks adjacent to a staffed service point, retrieval of concrete data on actual usage appears to be virtually unattainable. Survey data reported in this study is likely to underestimate Bike Desk use. Further investigation needs to be done on methods of tracking use or if this data is in fact desirable.

There are also limitations to the Bike Desks and the local implementation. Prior to the procurement of the Bike Desks, there was an awareness of potential mechanical concerns and the safety of library users. Online reviews had referred to a need to tighten pedals regularly and indicated that other movable parts may loosen as well. As the library took proactive measures and made periodic checks, these potential issues were addressed before they became problematic. However, over the course of the pilot, other issues were identified. Mechanical failures that had to be addressed included a slight over-tightening of two primary screws that attached the desktop to one unit, resulting in an unsteady table top. The nature of the damage led to communication with the manufacturer for replacement screws. This took one of the units located in the Evans Library out of commission for approximately three weeks.

As the Bike Desks came with a digital sensor unit for measuring energy output, some issues arose with faulty sensors on the MSL bikes, which also led to a delay in deployment while awaiting replacements from the manufacturer. Additionally, although not categorized as mechanical equipment failures, limitations were also identified that lessened the effectiveness of the student experience. Factors such as seat size, seat height (and how to adjust it), desktop size, 
location, and use of the digital display device resulted in survey and verbal feedback that indicated there would be opportunities for future improvements.

Despite some of the issues that arose, feedback from the survey was both positive and convincing enough to consider not IF to pursue a continuation of the Bike Desk project, but rather HOW to move forward addressing the limitations and providing additional enhancements where possible. Along with continuation of regular equipment checks, a continued effort must be made to identify improved or enhanced models that address equipment issues and decrease the library's need for dedicated employee resources towards the maintenance effort. The persistent desire for privacy when using the Bike Desks and the related distraction to those studying near the Bike Desks suggest that a dedicated space or room may be a more appropriate venue. To this end, Texas A\&M University Libraries will be investigating the creation of a dedicated "fitness room," where the Bike Desks and other potential health-related study options would be available. This would address concerns such as the need for fans (and the potential noises such devices might generate), privacy, human-generated noises, and provide for expansion to additional fitness devices. Such a room would also speak to a more serious library interpretation of student health and mental stimulation through physical activities.

\section{Conclusion}

The Bike Desk study at Texas A\&M University Libraries resulted in a number of interesting and worthwhile findings. The results captured and discoveries from data interpretation allow the 
library to move forward with the Bike Desks in a way that meets the demands of library clientele. A plan that focuses on solitary afternoon riding for approximate half-hour sessions would seemingly provide a high level of satisfaction with the students that come to the library for academic studies and research but also prefer to include exercise in their routine. Libraries have long been known for providing informational resources for academic success as well as instruction on how to effectively access those resources. The Bike Desks allow libraries to venture deeper into the concept of providing environmental stimulation that also contributes to a successful academic experience.

Along with the positive student response to the Bike Desks, the library received positive feedback from the profession as well. Libraries interested in engaging in similar projects should consider the following:

- Think carefully about the location of physical activities like Bike Desks in libraries. Users are concerned about privacy while using the equipment.

- Create a maintenance plan for the equipment, and make sure that the library has the necessary staff and budget to enact fixes should they be needed.

- Check the institution's requirements for liability policies regarding exercise equipment. Institutions may insist on the posting of approved disclaimer statements about using exercise equipment within one's building.

- Collection of data on usage is difficult if the equipment is placed in an open floor. Think carefully about how the library will measure the success of a Bike Desk project. 
- Marketing matters. Consistent marketing will support the continued use of Bike Desks throughout the academic calendar.

- Start with a small number of Bike Desks and see if they work in one's local environment before investing in a whole room of equipment.

There are very few projects exploring the effects of physical activity in library settings. This study represents one avenue that libraries can use to begin to engage library users in new and exciting ways.

\section{References}

Adams, S., Matthews, C., Ebbeling, C., Moore, C., Cunningham, J., Fulton J. and Herbert J. (2005). The effect of social desirability and social approval on self-reports of physical activity. American Journal of Epidemiology, 161(4):389-398.

Bryant, S. A., Walker, J. H., Bryan, R. C., Drummond, C. N., Macpherson, V. K., Morris, D. M.,...Pilcher, J. J. (2015). The influence of light activity on academic performance and sleep quality. Focus on Creative Inquiry (Paper No. 110).

Dinger, M. K. (1999). Physical activity and dietary intake among college students. American Journal of Health Studies, 15(3), 139-149.

Fox, K. R. (1999). The influence of physical activity on mental well-being. Public Health Nutrition, 2(3a), 411-418. 
Friends of Dacus Library. (2016, Spring). FitDesk bikes at Dacus. Friends of Dacus Library Newsletter, 10(3), 2. Retrieved from http://digitalcommons.winthrop.edu/dacusfriendsnewsletter/23

Logue, J. (2015, December 15). Study cycle. Inside Higher Ed. Retrieved from https://www.insidehighered.com/news/2015/12/15/college-libraries-install-desks-whichstudents-can-study-and-cycle

Nagane, M. (2004). Relationship of subjective chronic fatigue to academic performance. Psychological Reports, 95(1), 48-52.

Ng, S.W., \& Popkin, B. (2012). Time use and physical activity: A shift away from movement across the globe. Obesity Reviews, 13(8), 659-680.

Nolan, M. E. (2015). Bikes in the library: Pedaling for health, literacy, and green power. Journal of Consumer Health on the Internet, 19(3-4), 265-270.

Oka, R. K., De Marco, T., Haskell, W. L., Botvinick, E., Dae, M. W., Bolen, K., \& Chatterjee, K. (2000). Impact of a home-based walking and resistance training program on quality of life in patients with heart failure. The American Journal of Cardiology, 85(3), 365-369.

Pauline, J. S. (2013). Physical activity behaviors, motivation, and self-efficacy among college students. College Student Journal, 47(1).

"Pedal to the metal: Library among first in state to offer 'FitDesk'." (2016, February 3). News at $O U$. Retrieved from

https://wwwp.oakland.edu/newsatou/news/2016/kresge-library-among-first-in-state-to-offerfitdesk

Phillips, D. L., Clancy, K. J. (1972). Some Effects of "Social Desirability" in Survey Studies. American Journal of Sociology, Vol. 77(5), 921-940. 
Pilcher, J. J., \& Baker, V. C. (2016). Task performance and meta-cognitive outcomes when using activity workstations and traditional desks. Frontiers in Psychology, 7(957), 1-6.

Pilcher, J. J., Morris, D. M., Bryant, S. A., Merritt, P. A., \& Feigl, H. B. (2017). Decreasing sedentary behavior: Effects on academic performance, meta-cognition, and sleep. Frontiers in Neuroscience, 11(219), 1-8.

Riegel, J. (2017, February 27). Fitdesk pilot assessment. Retrieved from http://dukespace.lib.duke.edu/dspace/handle/10161/13691

Shaffer, C. (2016). Sweating in the stacks. American Libraries, 47(5), 22.

Soyeur, F., Unalan, D., \& Elmali, F. (2010). The relationship between physical activity level and fatigue in vocational college students. International SportMed Journal, 11(3), 345-355.

Stancill, J. (2015, December 9). Newfangled desks aim to end sedentary lifestyle of college students. The News \& Observer. Retrieved from http:/www.newsobserver.com/news/local/education/article48887400.html

Towne, S. D., Ory, M. G., Smith, M. L., Peres, S. C., Pickens, A. W., Mehta, R. K., \& Benden, M. (2017). Accessing physical activity among young adults attending a university: The role of sex, race/ethnicity, technology use, and sleep. BMC Public Health, 17(721), 1-11.

Villablanca, P. A., Alegria, J. R., Mookadam, F., Holmes, D. R., Jr., Wright, R. S., \& Levine, J. A. (2015). Nonexercise activity thermogenesis in obesity management. Mayo Clinic Proceedings, 90(4), 509-519.

Young, D. R., Hivert, M.-F., Alhassan, S., Camhi, S. M., Ferguson, J. F., Katzmarzyk, P. T.,...Yong, C. M. (2016). Sedentary behavior and cardiovascular morbidity and mortality: A science advisory from the American Heart Association. Circulation. 134(13), 262-279. 
Young, S. J., Sturts, J. R., \& Ross, C. M. (2015). Physical activity among community college students. Physical Educator, 72(4). 